\title{
RISCO DE SALINIZAÇÃO DAS TERRAS DO BAIXO ACARAÚ (CE) ${ }^{(1)}$
}

\author{
Lydia Helena da Silva de Oliveira Mota ${ }^{(2)}$, Andréa da Silva Gomes ${ }^{(3)}$, Gustavo Souza \\ Valladares $^{(4)}$, Regina Maria Fontenele Magalhães ${ }^{(5)}$, Hugo Mota Ferreira Leite ${ }^{(6)}$ \& \\ Tibério Almeida da Silva ${ }^{(7)}$
}

\begin{abstract}
RESUMO
Em determinadas condições de relevo, do clima e de uso, com certa frequência pode acontecer acúmulo de sais nos solos, dando lugar à formação dos solos salinos e sódicos - também denominados de solos afetados por sais. A fim de orientar as práticas de manejo e uso das terras da região do Baixo Acaraú, CE, objetivou-se com o presente trabalho gerar um mapa de risco de salinização. Para obtenção das classes de vulnerabilidade, foram avaliados os temas pedologia, geologia, geomorfologia e uso e cobertura das terras e informações de declividade e altimetria, tratados em ambiente SIG com o método multicritério aditivo. Foram definidas quatro classes de risco de salinização: baixo, moderado, alto e altíssimo ou solos naturalmente salinos/ sódicos. Foi constatado que $35,47 \%$ da área corresponde à classe de baixo risco de salinização; $26,22 \%$, à de risco moderado; 8,23 \%, à de risco alto; e $19,65 \%$, à de risco altíssimo.
\end{abstract}

Termos de indexação: SIG, multicritério, gestão agroambiental.

(1) Recebido para publicação em 11 de novembro de 2011 e aprovado em $1^{\circ}$ de junho de 2012 .

(2) Professora do Instituto Federal de Educação, Ciência e Tecnologia de Rondônia - IFRO, Campus Ji-Paraná, Rua Rio Amazonas, 151, Jardim dos Migrantes, CEP 76900-730, Ji-Paraná (RO). E-mail: lydia.mota@ifro.edu.br

(3) Mestranda do curso de Pós-graduação em Agronomia - Ciência do solo, Universidade Federal Rural do Rio de Janeiro - UFRRJ, Departamento de solos, BR 465 km 7, CEP 23890-000, Seropédica (RJ). E-mail: andrea_zooufc@yahoo.com.br

(4) Professor Adjunto, Universidade Federal do Piauí, Campus Universitário Ministro Petrônio Portella, S/N, Bairro Ininga, CEP 64049-550, Teresina (PI). E-mail: valladares@ufpi.edu.br

(5) Mestranda do curso de Pós-graduação em Nutrição Animal e Forragicultura, Universidade Federal do Ceará - UFC, Departamento de zootecnia, Campus do Pici, S/N, Blocos 808 e 809, Fortaleza (CE). E-mail: ginamaria00@hotmail.com

(6) Professor Assistente, Universidade Federal do Acre - UFAC, Campus Universitário de Cruzeiro do Sul, Estrada do Canela Fina, Km 12, Gleba Formoso, CEP 69980-000, Cruzeiro do Sul (AC). E-mail: enghmf@hotmail.com

(7) Estudante de Graduação em Agronomia, Universidade Federal do Ceará, Campus do Pici, S/N, Bloco 807, CEP 60021-970, Fortaleza (CE). E-mail: tiberioagro@gmail.com 


\title{
SUMMARY: RISK OF LAND SALINIZATION IN BAIXO ACARAÚ, CEARÁ
}

\begin{abstract}
Certain conditions of relief, climate and use can lead to the formation of saline and sodic soils, also called salt-affected soils. With a view to establish guidelines for management practices and land use in the region of Baixo Acaraú, Ceará, the purpose of this work was to generate a map of salinization risk. To classify levels of vulnerability, the pedology, geology, geomorphology and land use / cover were evaluated as well as slope altimetry information, treated in a GIS environment with an additive multi-criteria method. Four classes of salinization risk were defined: soils with naturally low, moderate, high, or very high salinity/sodicity. It was found that the risk of salinization was low in $35.47 \%$ of the area, moderate in $26.22 \%$, high in $8.23 \%$ and very high in $19.65 \%$.
\end{abstract}

Index Terms: SIG, multicriteria, agro-environmental management.

\section{INTRODUÇÃO}

A economia da região Nordeste tem sofrido grandes modificações devido à expansão da agricultura irrigada. Quando se compara a receita do cultivo irrigado com a do cultivo dependente de chuva, observa-se que ela é cerca de 10 vezes superior em anos normais (Valladares \& Faria, 2004). Ainda de acordo com esses autores, a irrigação tornou o ambiente nordestino vantajoso se comparado com o de outras regiões brasileiras, porque ele dispõe de insolação durante cerca de oito meses do ano e apresenta clima quente e seco - fatores essenciais da produção irrigada de frutas e hortaliças de qualidade.

No Brasil, as informações sobre áreas salinizadas ainda não são bem definidas, porém há estimativa de que 20 a $25 \%$ das áreas irrigadas, principalmente as que estão sob solos aluviais, apresentam problemas de salinidade e, ou, de drenagem. Existem também grandes áreas alteradas por causas naturais, o que corresponde a cerca de $2,4 \%$ do total da área do Brasil (FAO, 2008).

Se não forem adotadas medidas concretas de prevenção e controle, a intensificação e a expansão da área irrigada podem acelerar a ocorrência de alguns efeitos adversos sobre o solo (Mota, 2011). Segundo Ongley (2000), com a expansão das áreas irrigadas crescem também os problemas de degradação dos recursos naturais (solo e água), principalmente aqueles relacionados à salinidade e à sodicidade do solo. Esses problemas ocorrem sobretudo em regiões áridas e, ou, semiáridas, onde a precipitação pluvial anual não garante a lavagem dos sais acumulados (Lopes et al, 2008).

A irrigação mal conduzida provoca a salinização dos solos, inviabilizando algumas áreas e perímetros irrigados do semiárido (Accioly, 2000). O problema tem sido provocado tanto pelo tipo de sistema de irrigação, muitas vezes inadequado às características do solo, quanto pela maneira como a atividade é executada. Além disso, as características físicas, químicas e biológicas do solo, bem como as características físicas do meio natural (geomorfologia e geologia), também influenciam o processo de salinização (Valladares \& Faria, 2004).

De acordo com o Sistema Brasileiro de Classificação de Solos (Embrapa, 2006), o caráter sódico é utilizado para distinguir horizontes ou camadas do solo que apresentem saturação por sódio $\geq 15 \%$, e solódico, variando de 6 a $<15 \%$. Solos com caráter sálico são caracterizados por condutividade elétrica no extrato saturado maior ou igual a $7 \mathrm{dS} \mathrm{m}^{-1}\left(\right.$ a $\left.25^{\circ} \mathrm{C}\right)$, e salino, com valores entre 4 e $7 \mathrm{dS} \mathrm{m}^{-1}$. Segundo Ramalho Filho \& Beek (1995), condutividade elétrica do solo entre 4 e $8 \mathrm{dS} \mathrm{m}^{-1}$ e saturação por sódio entre 8 e $20 \%$ já representam grau de limitação moderado à agricultura por deficiência de fertilidade; a condutividade elétrica entre $8 \mathrm{e} 15 \mathrm{dS} \mathrm{m}^{-1}$ e a saturação por sódio superior a $15 \%$ indicam forte limitação ao desenvolvimento vegetal.

Segundo Smedema \& Shiati (2002), mesmo em uma visão conservacionista, nas regiões secas do globo são adicionados de três a cinco toneladas de sais por hectare irrigado por ano. Souza et al. (2000) afirmam que o processo de salinização em áreas irrigadas pode acontecer mesmo em solos com boas características, principalmente nas situações em que não existe manejo de solo e água adequados. O teor de sais nos solos irrigados possui ligação direta com a precipitação pluvial total anual, com as propriedades físicas do solo e com as condições de drenagem. Em condições favoráveis, esses sais poderão retornar ao rio ou ao aquífero de origem (Pereira et al., 1986; Ben-Hur et al., 2001).

Oliveira (1996) afirma que algumas medidas podem ser adotadas para diminuir os processos de salinização e sodificação dos solos, a saber: melhoria das condições de drenagem; avaliações periódicas do nível do lençol freático; análises periódicas do solo e das águas de irrigação e do lençol freático; manejo agrícola adequado e uso de culturas selecionadas em função de sua tolerância à salinidade e assistência técnica permanente aos irrigantes.

As geotecnologias relacionadas a sistemas de informações geográficas (SIG) e sensoriamento remoto são ferramentas facilitadoras da análise ambiental. 
Por meio de métodos multicritérios ou interpretação booleana, podem-se gerar mapas de risco de salinização, utilizando a base geográfica para as inferências (Mota, 2011). Os SIGs são conjuntos manuais ou computacionais de procedimentos (Aronoff, 1995) desenvolvidos para trabalhar com dados referenciados por coordenadas geográficas ou espaciais (Star \& Ester, 1990). Ou, segundo Cowen (1988) citado por INPE (1996), consistem em sistemas de suporte à decisão, integrando dados referenciados espacialmente em um ambiente de respostas a problemas.

O uso de SIGs permite obter mapas com rapidez e precisão, sendo uma ferramenta importante no estudo de potencialidades do ambiente; no caso da avaliação de áreas com risco de salinização, constitui-se em etapa importante para a definição de práticas adequadas de manejo e conservação do solo e da água (Valladares \& Faria, 2004).

Objetivou-se com este trabalho gerar um mapa de risco de salinização das terras da região do Baixo Acaraú, utilizando informações de declividade, altimetria, pedologia, geologia, geomorfologia e uso e cobertura das terras, tratadas em ambiente SIG, visando orientar as práticas de manejo e uso dos solos agrícolas.

\section{MATERIAL E MÉTODOS}

A região do Baixo Acaraú está inserida na bacia do rio Acaraú, a qual está localizada na região norte do Estado do Ceará, que é drenada exclusivamente pelo rio Acaraú e seus afluentes. Ocupa uma área da ordem de $14.416 \mathrm{~km}^{2}$, o que representa $9,73 \%$ da área do Estado do Ceará. A bacia do Acaraú possui aproximadamente $315 \mathrm{~km}$ de extensão e desenvolvese no sentido sul-norte (Cogerh, 2009). Aárea de estudo apresenta-se na porção mais baixa da bacia do rio Acaraú (Figura 1), correspondente aos municípios de Acaraú, Cruz, parte de Bela Cruz e de Marco, e ocupa um total de $1.067,22 \mathrm{~km}^{2}$.

Nessa região foi criado e implantado o Perímetro Irrigado Baixo Acaraú, que vem se expandindo até a presente data e corresponde a aproximadamente 11,6 $\%$ da área estudada. Ao sul e a leste, as coordenadas geográficas, em graus, aproximadas que delimitam a área são $2^{\circ} 48^{\prime}$ e $3^{\circ} 14^{\prime} \mathrm{S}$ e $40^{\circ} 15^{\prime}$ e $40^{\circ} 2^{\prime} \mathrm{W}$, com precipitação pluvial média anual em torno de $900 \mathrm{~mm}$, sendo o período seco de julho a dezembro e o chuvoso de janeiro a junho (SUDEC/DNOCS, 1974). A umidade relativa média varia de níveis $<50 \%$ a $>80 \%$; o primeiro ocorre nas regiões mais secas e nos meses de estiagem, e o segundo, nas regiões mais úmidas (Köppen \& Geiger, 1928). O relevo apresenta inclinação razoavelmente suave, porém com forte declividade longitudinal. Os solos, em geral, são profundos, bem drenados, de textura média/leve e muito permeáveis (DNOCS, 2009). Na figura 2 é apresentado o mapa de solos da área de estudo. Mais detalhes sobre a pedologia são encontrados em Mota (2011).
O mapa de risco de salinização foi gerado com o uso de um método multicritério ordinal aditivo, definido por Xavier-da-Silva (2001) como média ponderada. A integração entre SIG e Apoio

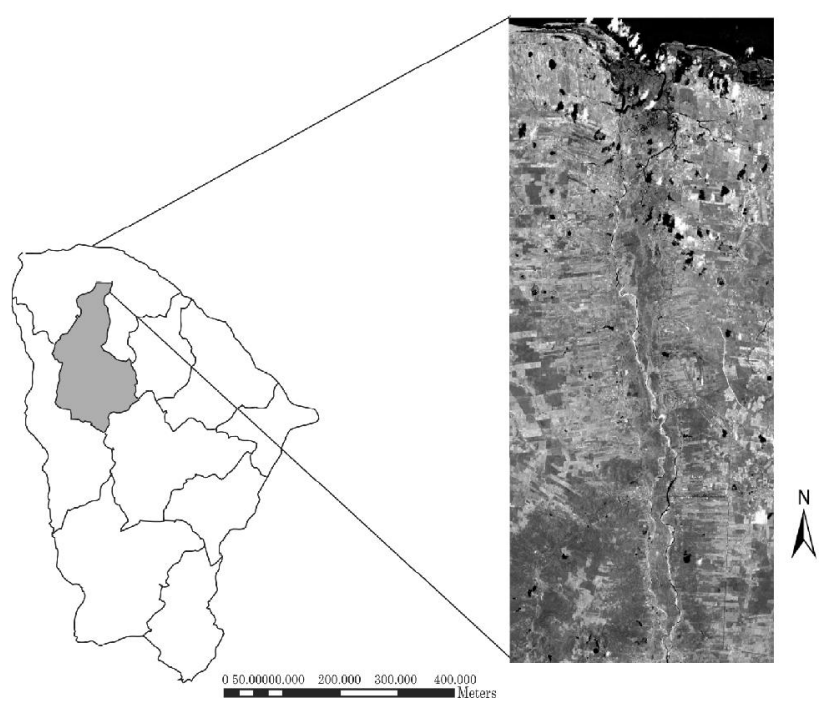

Figura 1. Representação do Estado do Ceará, com destaque para a área de estudo.

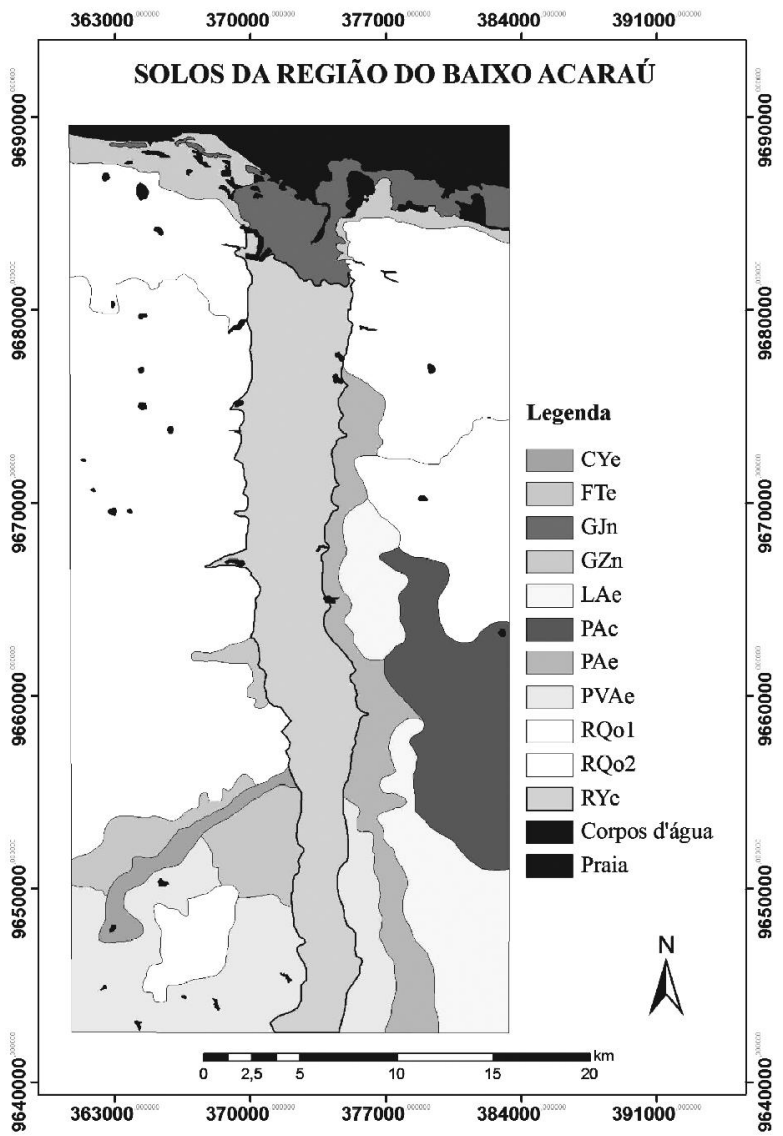

Figura 2. Mapa pedológico da região do Baixo Acaraú. 
Multicritério à Decisão é abordada na literatura (Gomes \& Estellita Lins, 2002).

Um algoritmo sugerido, usado em vários trabalhos sobre inferência espacial de riscos ambientais (Valladares \& Faria, 2004; Garcia et al., 2006; Meirelles et al., 2007; Faria et al., 2012) e que é adequado aos mapas raster utilizados, é apresentado a seguir (Eq. 1):

$$
\mathrm{Aij}=\Sigma \mathrm{n}(\mathrm{Pk} \times \mathrm{Nk})
$$

em que: $\mathrm{k}=1$; Aij = qualquer célula da matriz (alternativa); $\mathrm{n}=$ número de parâmetros envolvidos; $\mathrm{P}=$ peso atribuído ao parâmetro, transposto o percentual para a escala de 0 a $1 ; \mathrm{e} \mathrm{N}=$ nota na escala de 0 a 100, atribuída à categoria encontrada na célula.

O modelo foi aplicado individualmente aos temas, de forma a atribuir valores de risco para que fossem analisados em conjunto com os mapas temáticos da área de estudo, gerados por meio do software ArcGIS com a função RASTER CALCULATOR, permitindo o tratamento dos dados e as análises do risco de salinização dos solos.

Para realização das avaliações, foram utilizadas informações de declividade, pedologia, geologia, geomorfologia, uso e cobertura das terras e altimetria. A importância de cada evento analisado foi considerada em função do somatório dos produtos dos pesos relativos das variáveis escolhidas, multiplicado pelas notas das classes em cada unidade das células.

Os pesos e notas foram atribuídos com base na experiência e por consenso de equipe multidisciplinar especializada em meio físico e na interpretação de mapas de riscos ambientais. Os resultados quantitativos foram transformados em classes qualitativas, como, por exemplo, baixo, moderado, alto, muito alto, etc. Método semelhante foi empregado nos trabalhos de Crepani et al. (1996), Valladares et al. (2002) e Valladares \& Faria (2004).

O mapa de risco de salinização foi gerado utilizando o método multicritério mencionado, os pesos de $20 \%$ para o tema pedologia, $15 \%$ para geomorfologia, $20 \%$ para uso e cobertura das terras, $15 \%$ para geologia, $20 \%$ para altimetria e $10 \%$ para declividade. As notas do risco de salinização foram atribuídas às unidades de mapeamentos dos mapas de cada tema, numa escala de 0 a 10 , indicando que, quanto maior a nota, maior o risco de salinização da unidade de mapeamento. Para as áreas fora de análise - como corpos d'água, zona urbana, canal de irrigação e outras - foram atribuídas notas altíssimas (200).

\section{RESULTADOS E DISCUSSÃO}

O mapa de risco de salinização é apresentado na figura 3, e as classes de risco de salinização, no quadro 1. A legenda do mapa foi a seguinte: baixo, moderado, alto e altíssimo risco de salinização.
Observa-se que $35,47 \%$ da área foi classificada como baixo risco de salinização, e a classe de maior expressão geográfica compreendeu a $377,87 \mathrm{~km}^{2}$. Nessa classe ocorrem predominantemente os Neossolos Quartzarênicos, Latossolos e Argissolos Acinzentados, que apresentam boa drenagem, sem salinidade e sodicidade em ambientes com relevo plano ou suave ondulado nos tabuleiros costeiros. Segundo Araújo et al. (2005), os riscos de salinização são diminuídos em solos permeáveis e profundos, e os efeitos adversos podem demorar muito tempo para se manifestar ou, simplesmente, não ocorrer, mesmo que o manejo não seja ideal. Esses autores mencionam, ainda, que os Latossolos e os Argissolos têm sido os solos preferidos pela CODEVASF para instalação dos projetos de irrigação no São Francisco.

Em grande parte dessas áreas, o uso e cobertura das terras pertencem à vegetação arbóreo-arbustiva $\mathrm{e}$ vegetação mista. A primeira naturalmente não tem problema de salinização. As áreas com vegetação mista também oferecem baixo risco devido ao grande recobrimento dos solos pelos diversos tipos de vegetação encontrados nessas áreas, principalmente pela presença de muitos cajueiros. De acordo com Oliveira-

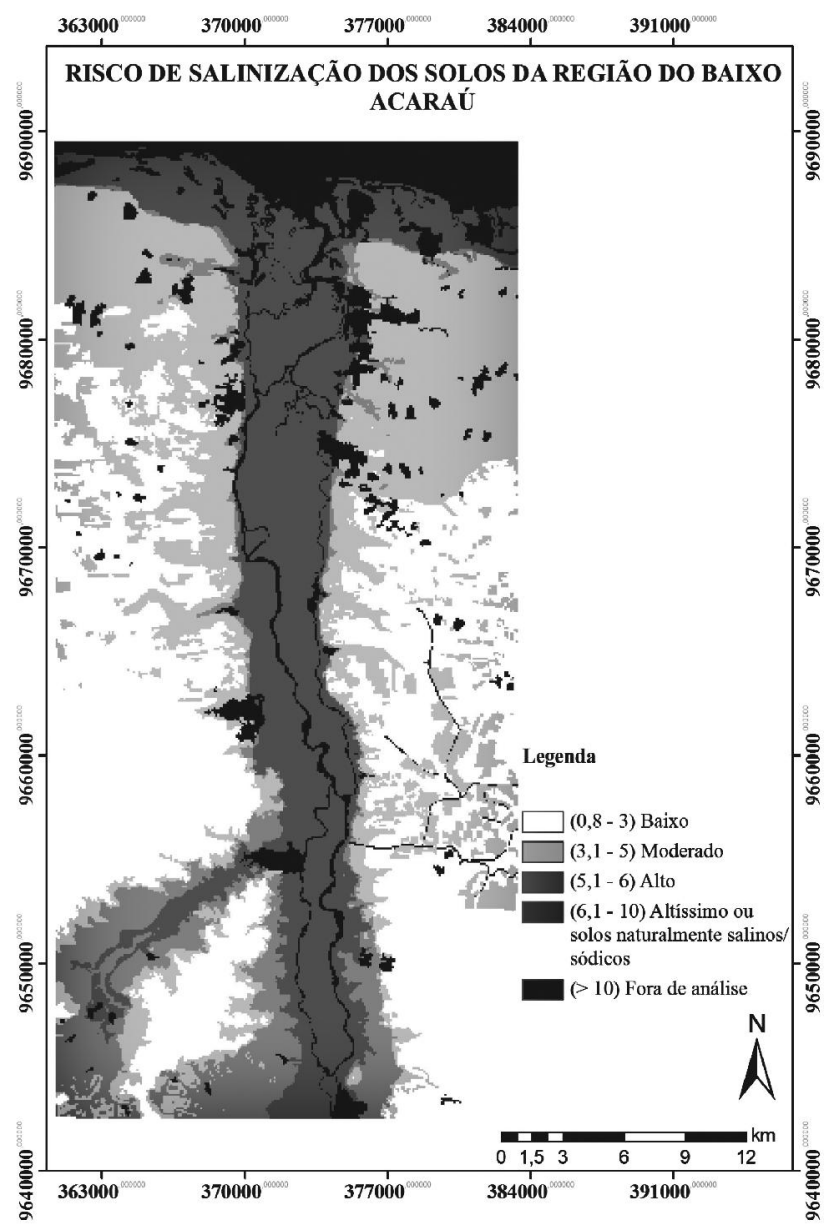

Figura 3. Mapa do risco de salinização das terras da região do Baixo Acaraú (CE). 
Quadro 1. Áreas das classes de risco de salinização das terras da região do Baixo Acaraú (CE)

\begin{tabular}{|c|c|c|c|}
\hline \multirow[t]{2}{*}{ Classe de risco de salinização } & \multicolumn{2}{|c|}{ Área } & \multirow[t]{2}{*}{ Grau } \\
\hline & $\mathrm{km}^{2}$ & $\%$ & \\
\hline Baixo & 377,87 & 35,47 & $0-3,0$ \\
\hline Moderado & 279,29 & 26,22 & $3,1-5,0$ \\
\hline Alto & 87,62 & 8,23 & $5,1-6,0$ \\
\hline Altíssimo ou solos naturalmente salinos/sódicos & 209,31 & 19,65 & $6,1-10$ \\
\hline Fora de análise & 111,12 & 10,43 & $>10$ \\
\hline TOTAL & $1.065,20$ & 100,00 & \\
\hline
\end{tabular}

Galvão (2001), a cobertura vegetal assume importante papel controlador dos processos de salinização; com os seus sistemas radiculares especializados, elas absorvem com eficiência a umidade da subsuperfície e mantêm relativo controle da elevação dos lençóis freáticos.

Quanto à geologia, as áreas com baixo risco de salinização são encontradas em parte do Grupo Barreiras Indiviso, nas zonas mais distantes da faixa litorânea. Segundo Oliveira-Galvão (2001), a composição local é uma característica fundamental para a potencialização do desenvolvimento de processos de salinização do solo e da água, pois esse substrato constitui a principal fonte natural de sais no ambiente.

A classe de risco moderado ocupa $26,22 \%$ da área e localiza-se principalmente na região dos tabuleiros costeiros mais próximos ao litoral; os solos predominantes são os Neossolos Quartzarênicos e os Argissolos Amarelos, todos eutróficos, em ambiente com maior influência de água salinizada. Essa classe é diretamente influenciada pela proximidade da faixa litorânea. Parte dessas áreas está inserida na região do Perímetro Irrigado Baixo Acaraú, em que o risco de salinização é maior, devido à irrigação, e ainda não é tão alto por causa do tempo de uso, e pelo fato de o manejo da irrigação ser por gotejamento. Segundo Batistella et al. (2008), o manejo agrícola do solo com irrigação pode ocasionar problemas de salinização.

Dessa forma, essas regiões podem ser diretamente alteradas, com maior risco de sofrerem salinização pela agricultura irrigada, seja por condições de manejo inadequado ou com águas de má qualidade, pela natureza eutrófica dos solos e pelas águas com elevada salinidade (Silva Filho et al., 2000; Valladares \& Faria, 2004; D'Almeida et al., 2005; Batistella \& Valladares, 2009). Nesse sentido, Souza et al. (2000) salientam que, nessas áreas com agricultura irrigada, o processo de salinização pode ocorrer mesmo em solos com boas características, principalmente nas situações em que não existe manejo de solo e água adequado. Almeida et al. (2006), em estudo sobre a qualidade das águas da bacia do rio Acaraú-CE para irrigação, verificaram que a maioria dos reservatórios estudados dessa bacia, no período de 2004 - 2005, apresentou, na grande totalidade de suas amostras, baixo risco de salinidade, o que torna suas águas aptas ao uso para quase todas as culturas, tornando-as viáveis à utilização nos perímetros de irrigação e por vazanteiros.

No entanto, é importante destacar que, mesmo as áreas do Perímetro Irrigado Baixo Acaraú estando classificadas como moderado risco de salinização, devese tomar cuidado e manejar esses solos adequadamente, pois, segundo Lannetta \& Colonna (2010), a salinização pode permanecer sem ser manifestada e detectada por anos, com níveis moderados de salinidade, enquanto um aumento adicional pode causar abandono das terras em poucos anos.

As áreas classificadas como alto risco de salinização ocupam $8,23 \%$ da área estudada e localizam-se nos pediplanos, associada a solos das classes Argissolo Vermelho-Amarelo e Plintossolo, com presença de horizonte B textural, eutróficos, em relevo de terço inferior a médio das encostas. Estes solos possuem drenagem e profundidade menores do que as dos solos das classes moderado e baixo. É importante ressaltar que os Plintossolos são formados sob condições de restrição à percolação de água e estão sujeitos ao excesso temporário de umidade, sendo, dessa forma, imperfeitamente a mal drenados (Embrapa, 2006) fatores esses que contribuem para o aumento do risco de salinização dessas áreas.

Outro fator relevante na classificação do risco de salinização dessas áreas com alto risco é que esses solos são originados de migmatitos, que podem fornecer íons pela ação do intemperismo, pois, segundo Figuerêdo (2005), a gênese de solos salinos está fortemente associada com a formação geológica predominante na paisagem e com a drenagem.

Essas áreas são ocupadas predominantemente por vegetação caducifólia seca com carnaúba; portanto, o solo fica bem exposto, favorecendo a evaporação, o que acarreta maior concentração de sais em sua superfície. De acordo com Lima et al. (2001), a presença ou não da cobertura vegetal tem grande influência na salinização dos solos, pois esta auxilia no controle da 
sua temperatura: solos afetados por sais apresentam temperaturas mais elevadas que os não afetados.

Assim, torna-se necessária a preservação desses ambientes, uma vez que mudanças na cobertura vegetal dessas áreas podem ocasionar sérios problemas, como a degradação progressiva da cobertura vegetal, os processos de erosão e de salinização, que constituem um dos principais processos degenerativos associados à desertificação (Lambin, 1993).

A classe de risco altíssimo ocupa 19,65\% da área estudada e corresponde às áreas da planície litorânea, restinga e planície fluvial. A planície litorânea é formada em sua totalidade de solos muito mal drenados, que sofrem influência das marés, em ambientes de mangue, com caráter sálico e tiomórfico. Segundo Sucupira (2006), a vegetação predominante do ambiente estuarino é a de mangue recobrindo os solos do tipo Gleissolos, os quais são muito mal drenados e apresentam padrões elevados de salinidade, o que está de acordo com o observado neste estudo.

Nas áreas de planície fluvial, que corresponde às terras de aluviões, predominam os Neossolos Flúvicos e Cambissolos, com algum impedimento à drenagem e risco de inundação no período chuvoso. Esses solos muitas vezes apresentam moderados a altos teores de bases, refletindo em caráter solódico (saturação por sódio entre 6 e $15 \%$ ) ou salino (condutividade elétrica

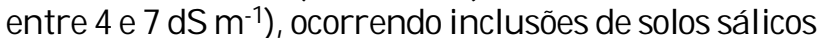
(condutividade elétrica $>7 \mathrm{dS} \mathrm{m}^{-1}$ ). Neles, o manejo deve dar prioridade às práticas que impeçam a salinização dos solos, como, por exemplo, drenagem artificial, água de irrigação de boa qualidade e manejo adequado da adubação (Gomes et al., 2010). Essas áreas são muito influenciadas pela dinâmica natural do ambiente, isto é, esses solos recebem influência do regime das marés e, ainda, sazonalmente, pela oscilação do nível freático, o que os leva a um altíssimo risco de salinização.

Essas áreas não são recomendadas para a agricultura irrigada, e grande parte dessas terras deve ser utilizada para preservação da fauna e flora.

\section{CONCLUSÕES}

1. O uso da avaliação multicritério em conjunto com o Sistema de Informações Geográficas mostrouse eficiente para avaliação do risco de salinização das terras do Baixo Acaraú.

2. O mapa de risco de salinização gerado pode servir como orientação aos agricultores no manejo dos solos e como informação para a gestão agroambiental das terras do Baixo Acaraú, por meio do poder público.

3. A localização do perímetro irrigado com vistas a evitar salinização dos solos mostrou-se adequada, porém o manejo deve ser cuidadoso, a fim de evitar ao longo dos anos a salinização.

\section{AGRADECIMENTOS}

Ao CNPq, à CAPES e à UFC, pela concessão de bolsas. Ao CNPq, pelo financiamento do projeto (Proc. 471433/2009 8).

\section{LITERATURA CITADA}

ACCIOLY, L.J.O. Degradação do solo e desertificação no Nordeste do Brasil. B. Inf. SBCS, 25:23-25, 2000.

ALMEIDA, M.M.M.; ALEXANDRE, A.M.B.; ARAÚJO, L.F.P.; FIGUEIREDO, M.C.B. \& ROSA, M.F. Qualidade das águas da bacia do Rio Acaraú - Ce para irrigação. In: SIMPÓSIO BRASILEIRO DE RECURSOS HÍDRICOS, 17., São Paulo, 2006. Anais... São Paulo, ABRH, 2006.

ARAÚJO, E.V.S.B.; ARAÚJO, M.S.B. \& SAMPAIO, Y.S.B. Impactos ambientais da agricultura no processo de desertificação no Nordeste do Brasil. R. Geogr., 22:90112,2005

ARONOFF, S. Geographic Information Systems: A management perspective. Ottawa, WDL Publications, 1995. 294p.

BATISTELlA, M.; VALLADARES, G.S. \& BOLFE, E.L. Monitoramento da expansão agropecuária como subsídio à gestão ambiental estratégica na Região Oeste da Bahia, Brasil. In: BATISTELLA, M. \& MORAN, E.F., eds. Geoinformação e monitoramento ambiental na América Latina. São Paulo, Senac São Paulo, 2008. p.163-195.

BATISTELLA, M. \& VALLADARES, G.S. Farming expansion and land degradation in western Bahia, Brasil. Biota Neotrop., 9:61-76, 2009.

BEN-HUR, M.; LI, F.H.; KEREN, R.; RAVINA, I. \& SHALIT, G. Water and salt distribution in a field irrigated with marginal water under high water table conditions. Soil Sci. Soc. Am. J., 65:191-198. 2001.

COMPANHIA DE GESTÃO DOS RECURSOS HÍDRICOS COGERH. A bacia hidrográfica do Acaraú. Fortaleza, 2009. Disponível em: <http://portal.cogerh.com.br/eixosde-atuacao/gestao-participativa/comites-de-bacias/comiteda-baciahidrografica-do-acarau>. Acesso em 10 maio de 2009.

CREPANI, E.; MEDEIROS, J.S.; AZEVEDO, L.G.; DUARTE, V.; HERNANDEZ, P. \& FLORENZANO, T. Curso de sensoriamento remoto aplicado ao zoneamento ecológicoeconômico. São José dos Campos, INPE, 1996. 25p.

D'ALMEIDA, D.M.B.A.; ANDRADE, E.M. \& MEIRELES, A.C.M. Importância relativa dos íons na salinidade de um Cambissolo na Chapada do Apodi, Ceará. Eng. Agríc., 25:615-21, 2005.

DEPARTAMENTO NACIONAL DE OBRAS CONTRA AS SECAS - DNOCS. Perímetro Irrigado Baixo-Acaraú. Disponível em: <http://www.dnocs.gov.br/php/canais/ engenharia/>. Acesso em 26 abr. de 2009. 
EMPRESA BRASIELIRA DE PESQUISA AGROPECUÁRIA EMBRAPA. Centro Nacional de Pesquisa de Solos. Sistema brasileiro de classificação de solos. 2.ed. Rio de Janeiro, Embrapa Solos, 2006. 306p.

FARIA, A.L.L.; VALLADARES, G.S. \& RODRIGUES, A.F. Bacia do Rio Coruripe (Alagoas-AL): Uma análise por geoprocessamento das áreas de susceptibilidade à erosão do solo. In: ASSIS, A.A.F; FARIA, A.L.L. (ed.). O onde e o quando: Espaço e memória na construção da História e da Geografia. Viçosa: Geographica, 2012. p. 254-273.

FOOD AND AGRICULTURE ORGANIZATION OF THE UNITED NATIONS - FAO. Extent and causes of saltaffected soils in participating countries. FAO - Land and Plant nutrition management service. Disponível em: <http://www.fao.org/ag/agl/agll/spush/topic2.htm\#top> Acesso em 25 dez. de 2008

FIGUERÊDO, A.F.R. Análise do risco de salinização dos solos da bacia hidrográfica do Rio Colônia - Sul da Bahia. Ilhéus, Universidade Estadual de Santa Cruz, 2005. 97p. (Tese de Mestrado)

GARCIA, J. M. P.; XAVIER-DA-SILVA, J.; GOES, M. H. B. \& DIAS, J. E. Avaliação ambiental por geoprocessamento para delimitação e classificação de áreas de susceptibilidade a movimentos de massa na região de Itatiaia no Estado do Rio de Janeiro. Caminhos da Geografia, 17: 199-209. 2006.

GOMES, A.S.; VALLADARES, G.S. \& MAGALHÃES, R.M.F. SIG na análise do risco de salinização das terras da região do Baixo Acaraú - CE. In: SIMPÓSIO BRASILEIRO DE SALINIDADE, Fortaleza, 2010. Anais... Fortaleza, Universidade Federal do Ceará, 2010.

GOMES, E.G. \& ESTELLITA LINS, M.P. Integrating geographical information systems and multi-criteria methods: A case study. Ann. Operat. Res., 116:243-269, 2002.

INSTITUTO NACIONAL DE PESQUISAS ESPAICAIS - INPE. Manual de operação do SPRING: versão 2.0.1. São José dos Campos, 1996. (URL: http://spring.dpi.inpe.br/spring/help).

KÖPPEN, W. \& GEIGER, R. Klimate der Erde. Gotha, Verlag Justus Perthes, 1928. Wall-map $150 \mathrm{~cm}$ x $200 \mathrm{~cm}$.

LAMBIN, E.F. Spatial scales and desertification. Desert. Control B., 23:20-23, 1993.

LANNETTA, M. \& COLONNA, N. Salinização. In: PROJETO LUCINDA, Land Care. Disertification Affected Areas. Fascículo B, n. 3. 2010. Disponível em: <http://geografia.fcsh. unl.pt/lucinda/booklets/B3_Booklet_Final_PT.pdf $>$. Acesso em 10 mar. 2011.

LIMA, C.O.; BARBOSA, M.P.; LIMA, V.L.A. \& SILVA, M.J. Uso de imagens TM/Landsat-5 e termometria na identificação e mapeamento de solos afetados por sais na região de Sousa, PB. R. Bras. Eng. Agríc. Amb., 5:361-363, 2001.

LOPES, J.F.B.; ANDRADE, E.M. \& CHAVES, L.C.G. Impacto da irrigação sobre os solos de perímetros irrigados na Bacia do Acaraú, Ceará, Brasil. Eng. Agríc., 28:34-43, 2008.

MEIRELLES, M.S.P.; MOREIRA, F.R. \& CAMARA, G. Técnicas de inferência espacial. In: MEIRELLES, M.S.P. \& CAMARA, G. \& ALMEIDA, C.M, eds. Geomática. Modelos e aplicações ambientais. Brasília: Embrapa Informação Tecnológica, 2007. p. 105-190.
MOTA, L.H.S.O. Dinâmica de uso e riscos ambientais das terras do Baixo Acaraú. Fortaleza, Universidade Federal do Ceará, 2011. 155p. (Tese de Mestrado)

OLIVEIRA-GALVÃO, A.L.C. Reconhecimento da susceptibilidade ao desenvolvimento de processos de desertificação no nordeste brasileiro, a partir da integração de indicadores ambientais. Brasília, Universidade de Brasília, Instituto de Geociências, 2001. 298p. (Tese de Doutorado)

OLIVEIRA, L.B. Avaliação da salinização dos solos sob caatinga do Brasil. In: ALVAREZ V., V.H.; FONTES, L.E.F. \& FONTES, M.P.F., eds. O solo nos grandes domínios morfoclimáticos do Brasil e o desenvolvimento sustentado. Viçosa, MG, Sociedade Brasileira de Ciência do Solo, 1996. p.113-123.

ONGLEY, E.D. Controle da poluição da água pelas atividades agrícolas. Campina Grande, Universidade Federal da Paraíba, 2000. 92p.

PEREIRA, O.J.; MATIAS FILHO, J. \& ANDRADE, E.M. Variação do teor de sais no solo irrigado por aspersão e ação da chuva na sua lixiviação. R. Ci. Agron., 17:61-5, 1986.

RAMALHO FILHO, A. \& BEEK, K.J. Sistema de avaliação da aptidão agrícola das terras. 3.ed. Rio de Janeiro, EmbrapaCNPS, 1995. 65p.

SILVA FILHO, S.B.; CAVALCANTE, L.F.; OLIVEIRA, F.A.; LIMA, E.M. \& COSTA, J.R.M. Monitoramento da qualidade da água e acúmulo de sais no solo pela irrigação. Irriga, 5:112-115, 2000.

SMEDEMA, L.K. \& SHIATI, K. Irrigation and salinity: a perspective review of the salinity hazards of irrigation development in the arid zone. Irrig. Drain. Syst., 16:16174, 2002.

SOUZA, L.C.; QUEIROZ, J.E.; MEDEIROS, J.F. \& GHEYI, H.R. Variabilidade espacial da salinidade de um solo aluvial no semi-árido paraibano. R. Bras. Eng. Agríc. Amb., 4:35$40,2000$.

STAR, J. \& ESTER, J. Geographic information systems: an introduction. Englewood Cliffs, Prentice Hall, 1990. 303p.

SUCUPIRA, P.A.P. Indicadores de degradação ambiental dos recursos hídricos superficiais no Médio e Baixo Vale do Rio Acaraú - Ce. Fortaleza, Universidade Federal do Ceará, 2006. 242p. (Tese de Mestrado)

SUDEC/DNOCS. Levantamento de reconhecimento dos solos de parte do Vale Acaraú. Fortaleza, SUDEC, 1974. 183p.

VALLADARES, G.S. \& FARIA, A.L.L. SIG na análise do risco de salinização na bacia do Rio Coruripe, AL. Engevista, 6:86-98, 2004.

VALLADARES, G.S.; GUIMARÃES, M \& BATISTELLA, M. Susceptibilidade à erosão das terras na Região Oeste do Estado da Bahia. Campinas: Embrapa Monitoramento por Satélite, 2002. 9 p. (Comunicado Técnico 10).

XAVIER-DA-SILVA, J. Geoprocessamento para análise ambiental. Rio de Janeiro, Edição do Autor, 2001. 228p. 
